\title{
Interaction of Developmental Venous Anomalies with Resting-State Functional MRI Measures
}

\author{
(D) B. Sundermann, DB. Pfleiderer, (D) Hinnerup, DK. Berger, and (D). Douaud
}

\begin{abstract}
BACKGROUND AND PURPOSE: Functional MR imaging of the brain, used for both clinical and neuroscientific applications, relies on measuring fluctuations in blood oxygenation. Such measurements are susceptible to noise of vascular origin. The purpose of this study was to assess whether developmental venous anomalies, which are frequently observed normal variants, can bias fMRI measures by appearing as true neural signal.
\end{abstract}

MATERIALS AND METHODS: Large developmental venous anomalies (1 in each of 14 participants) were identified from a large neuroimaging cohort $(n=814)$. Resting-state fMRI data were decomposed using independent component analysis, a data-driven technique that creates distinct component maps representing aspects of either structured noise or true neural activity. We searched all independent components for maps that exhibited a spatial distribution of their signals following the topography of developmental venous anomalies.

RESULTS: Of the 14 developmental venous anomalies identified, 10 were clearly present in $17 \mathrm{fMRI}$ independent components in total. While 9 (52.9\%) of these 17 independent components were dominated by venous contributions and 2 (11.8\%) by motion artifacts, 2 independent components (11.8\%) showed partial neural signal contributions and 5 independent components (29.4\%) unambiguously exhibited typical neural signal patterns.

CONCLUSIONS: Developmental venous anomalies can strongly resemble neural signal as measured by fMRI. They are thus a potential source of bias in fMRI analyses, especially when present in the cortex. This could impede interpretation of local activity in patients, such as in presurgical mapping. In scientific studies with large samples, developmental venous anomaly confounds could be mainly addressed using independent component analysis-based denoising.

ABBREVIATIONS: BOLD = blood oxygen level-dependent; DVA = developmental venous anomaly; $\mathrm{IC}=$ independent component; ICA $=$ independent component analysis; rsfMRI = resting-state fMRI

Eunctional MR imaging of the brain is extensively used for taskspecific presurgical functional mapping ${ }^{1-3}$ and for task-based

Received May 10, 2018; accepted after revision August 25.

From the Nuffield Department of Clinical Neurosciences (B.S., G.D.), Oxford Centre for Functional MRI of the Brain (FMRIB), Wellcome Centre for Integrative Neuroimaging, University of Oxford, Oxford, UK; Institute of Clinical Radiology (B.S., B.P.), Medical Faculty, University of Münster and University Hospital Münster, Münster, Germany; and Department of Epidemiology and Social Medicine (H.M., K.B.), University of Münster, Münster, Germany.

B.S. was funded by a research fellowship from the Deutsche Forschungsgemeinschaft (SU 917/1-1). BiDirect is funded by a research grant (01ER0816 and 01ER1506) from the German Federal Ministry of Education and Research. H.M. was funded by a German Federal Ministry of Education and Research grant (01ER1205). G.D. was supported by the UK Medical Research Council (MR/K006673/1).

Preliminary results of this work previously presented at: Annual Meeting of the European Society of Neuroradiology, September 13-17, 2017; Malmö, Sweden.

Please address correspondence to Benedikt Sundermann, MD, Institute of Clinical Radiology, Medical Faculty, University of Münster, and University Hospital

Münster, Albert-Schweitzer-Campus 1, 48149 Münster, Germany; e-mail:

benedikt.sundermann@uni-muenster.de

- Indicates open access to non-subscribers at www.ajnr.org group studies. ${ }^{4}$ Analyses of spontaneous brain activity and connectivity by resting-state fMRI (rsfMRI) $)^{5-9}$ have been more recently introduced as a potential clinical tool, both in presurgical motor ${ }^{10,11}$ and language mapping, ${ }^{10,12-15}$ particularly in patients less able to adhere to task instruction, and mapping of epileptogenic foci. ${ }^{8}$ Additionally, rsfMRI combined with automatic machine learning shows promise for individual diagnosis and prognosis estimation in large datasets, especially in psychiatric and neurodegenerative disorders, ${ }^{16-19}$ as well as for genome-wide association studies. ${ }^{20}$ fMRI is based on blood oxygen level-dependent (BOLD) contrast and thus provides indirect measures of neural activity. BOLD changes are attributed predominantly to both extravascular tissue and local capillaries and veins. ${ }^{21}$ Consequently, there are various sources of potential bias to the BOLD

Indicates article with supplemental on-line tables.

Indicates article with supplemental on-line photos.

http://dx.doi.org/10.3174/ajnr.A5847 
signal measured by fMRI, including global and local perfusion as well as vascular architecture. ${ }^{21}$

Incidental findings and normal variants are frequently encountered in brain MR imaging. ${ }^{22-26}$ While debates on the management of incidental findings in scientific studies mostly focus on participant safety, ${ }^{27}$ little is known about potential biases of particular findings on measures of scientific or clinical interest (putative correlates of neural signals) in fMRI.

Developmental venous anomalies (DVAs) ${ }^{28}$ are frequent (around 2\% prevalence ${ }^{29,30}$ ) and are usually clinically irrelevant but can be associated, in rare circumstances, with other vascular lesions, such as cavernous malformations, or with abnormalities of neuronal migration. ${ }^{28,31}$ DVAs can also exhibit signs of venous congestion. $^{32}$ The normal venous drainage of the cerebral hemispheres can be divided into 2 systems: 1 ) The superficial system drains blood from cortical and immediately subcortical capillaries into pial veins; and 2) the deep system drains large parts of the deep white matter and basal ganglia into deep veins (the internal cerebral veins and the basal vein of Rosenthal). The cerebellum features a comparable, 2-system venous angioarchitecture. ${ }^{31}$ The term DVA describes variants in which a superficial venous territory drains into deep veins or a deep venous territory drains toward either the superficial pial veins or directly into a dural venous sinus. ${ }^{31}$

The detectability of DVAs depends largely on the imaging techniques used. However, DVAs are characterized by very typical morphologic imaging features. These are large collector veins crossing the brain parenchyma in locations where usually only capillaries and small veins are expected, and radially contributing veins resulting in a typical caput medusae appearance. ${ }^{29,31}$ These veins drain blood from an atypical territory. The presence of a DVA thus potentially undermines common assumptions about the origin of observed BOLD signal fluctuations in gray matter regions.

The purpose of this study was to assess if and how DVAs bias fMRI measures by assessing the similarity of DVA correlates in rsfMRI to typical patterns of neural activity in a large, community-based imaging population. ${ }^{33}$ If such similarity exists, then the presence of DVAs might lead to misinterpretations of local activity patterns in presurgical mapping and confound conclusions in group studies and new rsfMRI-based diagnostic approaches.

\section{MATERIALS AND METHODS \\ Subjects}

This analysis is based on subjects with large DVAs identified during routine radiologic review and quality assessment of brain MR imaging for the BiDirect cohort study. ${ }^{33,34}$ They were selected from a mixed sample of patients with depression and populationdwelling controls $(n=814)$. The study was approved by the local ethics committee, and all subjects gave their written informed consent. Demographic characteristics of the BiDirect cohort and the imaging sample used here are presented in On-line Table 1.

\section{MR Imaging Data Acquisition}

Structural and functional MR imaging data were acquired using a 3T scanner (Intera with an Achieva upgrade; Philips Healthcare,
Best, the Netherlands) and a standard transmit/receive head coil. Full details on the imaging protocol have been published separately. ${ }^{33}$

The main analyses were based on the following sequences: a 3D T1-weighted gradient-echo sequence with an inversion prepulse-turbo field echo, TR/TE $=7.26 / 3.56 \mathrm{~ms}$, TI $=404 \mathrm{~ms}$, flip angle $=9^{\circ}$, sagittal orientation, matrix $=256 \times 256 \mathrm{~mm}$, field of view $=256 \times 256 \times 160 \mathrm{~mm}$, voxel size $=1 \times 1 \times 2 \mathrm{~mm}$ reconstructed to $1 \times 1 \times 1 \mathrm{~mm}$ by zero-filling in the $k$-space; rsfMRI using a $2^{\star}$-weighted echo-planar imaging techniquefast-field echo, TR/TE $=3000 / 38 \mathrm{~ms}$, flip angle $=90^{\circ}, 72$ volumes, matrix dimensions $=64 \times 64, \mathrm{FOV}=230 \times 230 \mathrm{~mm}, 36$ axial slices, thickness $=3.6 \mathrm{~mm}$, pixel size $=3.6 \times 3.6 \mathrm{~mm}$.

Additional information about DVA morphology was obtained from the following: FLAIR-TR/TE $=11,000 / 80 \mathrm{~ms}$, TI $=2600$ $\mathrm{ms}$, flip angle $=90^{\circ}$, matrix dimensions $=352 \times 206$, FOV $=$ $230 \times 186 \mathrm{~mm}, 27$ axial slices, thickness $=4 \mathrm{~mm}$, gap $=1 \mathrm{~mm}$, reconstructed pixel size $=0.45 \times 0.45 \mathrm{~mm}$; and a $\mathrm{T} 2^{\star}$-weighted fast-field echo sequence $-\mathrm{TR} / \mathrm{TE}=574 / 16 \mathrm{~ms}$, flip angle $=18^{\circ}$, matrix dimensions $=256 \times 164, \mathrm{FOV}=230 \times 183 \mathrm{~mm}, 27$ axial slices, thickness $=4 \mathrm{~mm}$, gap $=1 \mathrm{~mm}$, reconstructed pixel size $=$ $0.45 \times 0.45 \mathrm{~mm}$.

\section{DVA Identification}

Suspected DVAs were confirmed in a separate step after initial screening during visual data-quality assessment based on T1weighted images using the following criteria: 1) a large vessel crossing the brain parenchyma, and 2) a typical caput medusae appearance of feeding vessels. Finally, a typical hypointense appearance was confirmed on $\mathrm{T}^{*}$ fast-field echo. We excluded subjects with signs of other associated vascular lesions, for example, cavernous malformations. FLAIR images were inspected for surrounding hyperintensity as a potential sign of venous congestion. ${ }^{32}$ Demographic information about all subjects selected for the DVA analysis as well as DVA locations is presented in On-line Table 2 .

\section{Resting-State fMRI Data Analysis with Independent Component Analysis}

Spatial independent component analysis (ICA) refers to a range of data-driven analysis techniques decomposing time-series data into a set of spatially independent components (ICs) characterized by spatial maps and signal time courses. ICA is particularly popular for the analysis of rsfMRI data because it can isolate separate representations of well-known functionally relevant brain networks. ${ }^{35}$ In addition to these components related to the signal of interest originating from the gray matter, further components represent distinct sources of noise such as arterial or CSF pulsations or movement artifacts. ${ }^{36}$ ICA is therefore very suitable for identifying and characterizing such biasing influences. ICA can identify general sources of noise independent of specific model assumptions in other fMRI analysis techniques. Thus, findings from ICA generalize to other analysis techniques and to taskfMRI data. Indeed, it can reveal potential biases that might have otherwise not been directly visible despite potentially significantly influencing results and conclusions. ICA is therefore increasingly applied as a preprocessing step for noise clean-up of both rsfMRI 
and task-fMRI data before performing further analyses (see the Discussion for details). ${ }^{36-38}$

Two types of components representing venous signal fluctuations are particularly relevant for DVAs: those showing mainly the venous sinuses and large veins and those putatively representing transmedullary and subependymal veins (traditionally referred to as white matter components). Given the partially venous origin of the BOLD signal of interest, venous noise components can exhibit temporal characteristics that greatly resemble signal components. ${ }^{36}$ Thus, additional spatial features (eg, based on sinus masks) have to be used in automatic noise-classification tools, ${ }^{37}$ but the underlying spatial assumptions behind these predefined masks could be broken in the presence of a large DVA.

Single-session analyses of the rsfMRI time-series data were conducted using the FMRIB Software Library (FSL, Version 5.0.9; http://www.fmrib.ox.ac.uk/fsl). ${ }^{39,40}$ Preprocessing included motion correction, ${ }^{41}$ non-brain tissue masking, ${ }^{42}$ spatial smoothing using a Gaussian kernel (full width at half maximum $=7 \mathrm{~mm}$ ), and high-pass temporal filtering (cutoff period $=100$ seconds). The resulting image time-series were then decomposed using probabilistic ICA with automatic dimensionality estimation as implemented in MELODIC (Version 3.15; https://fsl.fmrib. ox.ac.uk/fsl/fslwiki/MELODIC). ${ }^{35,43-45}$

\section{Identification of DVAs in the ICA Decomposition of rsfMRI}

To help with the identification of the presence of DVAs in our ICA, we linearly registered ICA spatial maps to the T1-weighted anatomic images using boundary-based registration. ${ }^{46}$ ICA spatial maps were thresholded at $|Z|=2.3$ and overlaid with anatomic images with FSLeyes (Version 0.9.11; https://fsl.fmrib. ox.ac.uk/fsl/fslwiki/FSLeyes). Components were individually assessed for contributions spatially corresponding to the courses of the DVAs (B.S.). Those ICs that were identified as containing DVA rsfMRI signal correlates were subsequently evaluated for whether they exhibited contributions of neural signal of interest or artifacts (eg, motion or arterial pulsations) by taking spatial maps, time courses, and power spectra into account. ${ }^{36}$

\section{RESULTS}

\section{General DVA Characteristics}

Sixteen DVAs without an associated second vascular lesion were identified in 16 subjects. None of the DVAs exhibited associated hyperintensities on FLAIR, kinking of the draining vein, or other indirect signs of venous congestion. Two of these findings located in the cerebellum were excluded from further analyses because they were partially cut by the fMRI acquisition volume.

\section{DVA Occurrence in the ICA Decomposition of rsfMRI}

All of the 14 DVAs subsequently included were present in at least 1 IC. Ten DVAs (71.4\%) had unique local presence, closely following their spatial distribution in at least 1 IC per subject and up to 4 ICs per subject. The remaining 4 DVAs had less specific spatial coverage. In other words, it could not be determined whether alterations in ICs corresponding to these 4 DVAs (at least 1 IC per subject) were directly related to the DVA or whether these alterations represented signal fluctuations of interest in the surrounding tissue or other sources of noise.

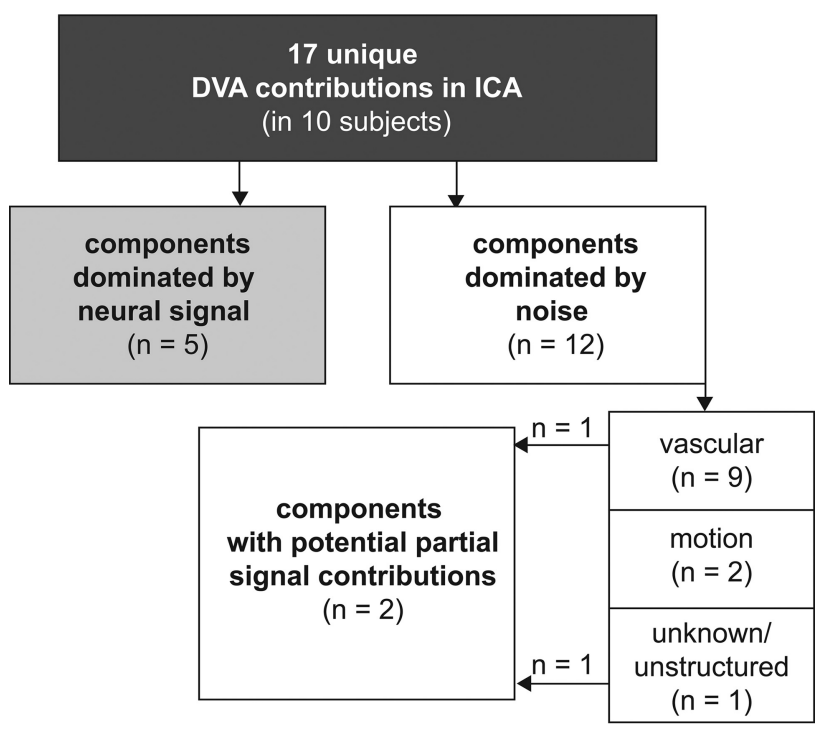

FIG 1. Overview of dominant effects represented by the independent components which included unique contributions of DVAs.

In total, 43 ICs thus covered spatial locations specific to DVAs across subjects. Seventeen of these ICs (39.5\%) exhibited unique contributions following the spatial distribution of the DVAs, while a further 26 ICs $(60.5 \%)$ were less specific, with their spatial distribution only partially overlapping that of the DVAs.

\section{Characteristics of rsfMRI ICs Containing DVAs}

Among the 17 ICs closely following the spatial distribution of the DVAs, 9 (52.9\%) were ICs with predominantly vascular patterns and clear contributions of venous sinuses, deep cerebral veins, or subependymal veins (white matter components), one of which exhibited partial signal contribution. Two ICs (11.8\%) were dominated by motion artifacts. Most important, 5 ICs (29.4\%) in 3 subjects exhibited dominant patterns typical of true neural signal. Three of these 5 ICs had clean low-frequency power spectra, while contamination in the higher frequency range was present in 2 ICs. One final IC was unstructured in its overall spatial distribution but showed partial overlap with neural signal (see Fig 1 for an overview of these results).

Illustrative cases are presented in Figs 2 and 3. A full list of the sample including DVA-related findings is presented in On-line Table 2. All 17 ICs distinctly following the spatial distribution of the DVAs are presented in On-line Figs 1-10.

\section{DISCUSSION}

In summary, most DVAs clearly appeared in $\geq 1$ component on the basis of ICA decomposition of the rsfMRI data. While some of these ICs demonstrated unambiguous venous ICs including the venous sinuses, some of the DVAs were present in ICs that mostly exhibited typical features of neural signal ICs or that could not be unambiguously classified as noise. These findings show that signal fluctuations in DVAs can contribute to the fMRI signal in the brain and thus have the potential to bias conclusions in both clinical and scientific fMRI analyses if not appropriately considered, especially in a superficial/cortical location. DVAs could thus lead to pseudoactivations in presurgical mapping, biasing the possible extent of subsequent tumor resection if not recognized. 


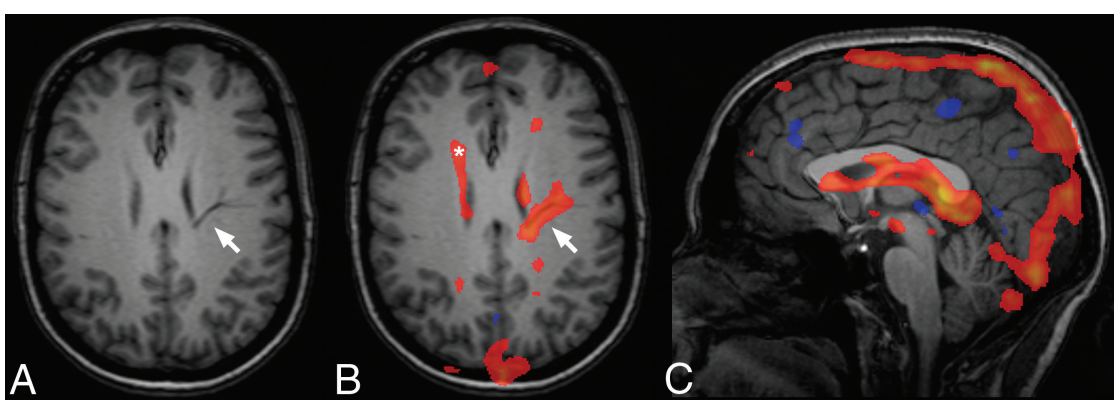

FIG 2. An example of a unique contribution of a DVA with deep drainage in an IC dominated by venous pulsations (subject 5). Typical anatomic features of the DVA (arrow, A) with a caput medusae appearance, unique contribution following the course of the DVA through the parenchyma (arrow, B) and contributions attributable to normal subependymal veins in the periventricular white matter (asterisk, B). C, Midsagittal view representing the typical venous character of this component, including venous sinuses and deep veins.

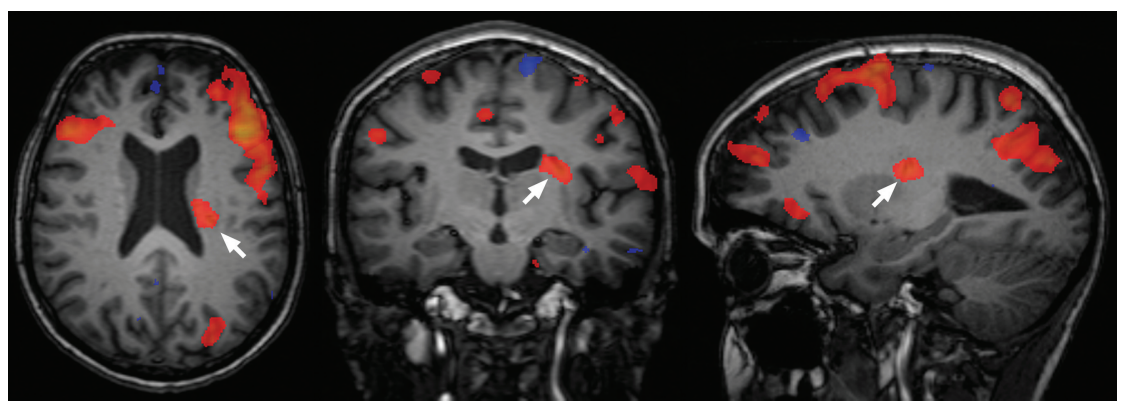

FIG 3. An example of a unique contribution of a DVA (arrows) in an IC exhibiting typical characteristics of a neural signal component (subject 3).

Local pseudoactivity might also bias conclusions in the rsfMRI group studies, focusing on disease mechanisms, particularly in small samples. Finally, altered activity patterns may lead to false individual diagnostic decisions in highly automated diagnostic modeling, for example, when a classifier (supervised learning) is applied to rsfMRI data biased by a DVA in a single subject.

Potentially strong biases of vascular abnormalities on fMRI measures are well-known from imaging in patients with arteriovenous malformations, which are high-flow lesions. ${ }^{1,47}$ Our findings demonstrate that such biases can also be caused by usually clinically irrelevant low-flow lesions such as DVAs. Perfusion imaging in DVAs has revealed a diverse pattern: The large collector veins typically present as strictly local hyperperfusion compared with the surrounding brain parenchyma. Surrounding brain tissue can either exhibit normal perfusion patterns ${ }^{48}$ or show signs of venous congestion with delayed perfusion and increased cerebral blood volume extending beyond the visible transparenchymal vessels. ${ }^{32,48-52}$ Such venous congestion may be due to a rare stenosis of the draining vein ${ }^{31}$ and could further invalidate assumptions of fMRI in the affected area. We did not observe indirect signs of such venous congestion in our sample. Evidence of a more widespread influence of DVAs on adjacent brain tissue is provided by findings of reduced uptake of fluorodeoxyglucose in a subset of subjects with DVAs, suggesting hypometabolism. ${ }^{53}$

In addition to identification of interpretable signal components, ${ }^{36}$ ICA has a practical application for reduction of such biases. Indeed, it can be used to separate signals of interest from noise in fMRI data based on either hand classification of $\mathrm{ICs}^{36,54}$ or by using automated IC classification tools. ${ }^{36,37,55-65}$ Our results suggest that biasing signal fluctuations in DVAs can not only be identified but also addressed by ICA-based denoising in most cases. However, our results also demonstrate that a non-negligible proportion of DVAs cannot be reasonably separated from the neural signal of interest and may contaminate clear signal ICs, as well as unclear ICs (which are typically not removed from the dataset with these cleaning methods). The cooccurrence of DVA signal and typical neural signal patterns might be mainly based on similarly low (and potentially aliased) frequencies of the BOLD signal fluctuations in the temporal domain. We therefore believe that this observation points to the typical problem that the indirect measurement of neural activity by BOLD fMRI can be confounded by vascular sources of noise. ${ }^{55}$ In our opinion, this aspect is underappreciated in many fMRI and particularly rsfMRI studies, and both researchers and clinical personnel should be more aware of this general issue.

Another practically important finding is that the significant signal alterations related to DVAs strictly followed the spatial distribution of the collecting vein and large tributaries. This finding supports the idea that a potential bias is relatively local, though subthreshold alterations in the immediate vicinity cannot be excluded.

An important-but-controversial differential diagnostic aspect is the rare observation of arteriovenous malformations draining into DVAs or microshunts. ${ }^{66,67}$ While the latter is primarily an angiographic finding, whether the observation of DVA signal fluctuations with arteries, rather than with veins, might add to the diagnostic information in such cases remains to be evaluated. However, current temporal resolution typically below the frequency of arterial pulsations does not facilitate reliable diagnostic assessment of this issue due to aliasing. ${ }^{38,68}$

\section{Limitations}

This analysis focused on large DVAs clearly identifiable by their typical branching morphology (ie, no hard size criterion). Because 3D susceptibility-weighted imaging or contrast-enhanced T1-weighted data were not available in this sample, the true DVA prevalence is probably underestimated. Thus, the sample size of 14 subjects with clear DVAs in this study is comparatively small. In particular, DVAs with a superficial drainage pattern were potentially underrepresented because they can be more difficult to identify by nonenhanced MR imaging. We expect superficial DVAs to be more problematic, even if smaller, because the spatial interpretation of the signal origin (cortex versus DVA) is more difficult in these cases. Because we did not observe rare DVAs with signs of venous congestion in our substantial cohort of 814 participants, we unfortunately could not assess how rsfMRI captures 
this clinically relevant information. While focusing on ICA outputs might be perceived at first as a limitation, this analysis method actually provides an unbiased way to assess the true characteristics of the DVA signal and therefore its potential bias.

\section{CONCLUSIONS}

This work provides a proof of concept that DVAs can have features very similar to those of neural signal patterns and can thus potentially be a source of bias in fMRI analyses, probably especially when present in a superficial location involving the cortex. Thus, our study raises awareness of a potential issue that has been neglected so far. Although most effects of DVAs on fMRI signal were local and potentially amenable to dedicated noise-correction methods, there is evidence of more widespread alterations and a contamination of putative neural signal. In the clinical setting, physicians should be aware of potential "pseudoactivations" caused by DVAs, especially in the context of presurgical mapping, as well as potential biases these could cause in highly automated diagnostic approaches using supervised learning ${ }^{16-19}$ in big data and genome-wide association studies. ${ }^{20}$ DVAs in brain regions of interest could bias conclusions in small-group studies and thus warrant exclusion on a case-by-case basis.

Even though DVAs are usually not a clinically relevant finding, they should thus be reported to researchers by radiologists or neuroradiologists involved in the routine evaluation of scientific MR images of the brain. Awareness of potential biases caused by these frequent normal variants is important not only for neuroscientists but also for correct interpretation of clinical fMRI data.

\section{ACKNOWLEDGMENTS}

The authors thank all study participants and the entire team of the BiDirect study, including collaborators in associated institutions.

Disclosures: Benedikt Sundermann—RELATED: Grant: Deutsche Forschungsgemeinschaft, Comments: research fellowship SU 917/1-1. Heike Minnerup-RELATED: Grant: German Federal Ministry of Education and Research, Comments: grants 01ER1205, 01ER0816, and 01ER1506.* Klaus Berger—RELATED: Grant: German Ministry of Research and Education. * Money paid to the institution.

\section{REFERENCES}

1. Bartsch AJ, Homola G, Biller A, et al. Diagnostic functional MRI: illustrated clinical applications and decision-making. J Magn Reson Imaging 2006;23:921-32 CrossRef Medline

2. Leuthardt EC, Allen M, Kamran M, et al. Resting-state blood oxygen level-dependent functional MRI: a paradigm shift in preoperative brain mapping. Stereotact Funct Neurosurg 2015;93:427-39 CrossRef Medline

3. Gabriel M, Brennan NP, Peck KK, et al. Blood oxygen level dependent functional magnetic resonance imaging for presurgical planning. Neuroimaging Clin N Am 2014;24:557-71 CrossRef Medline

4. Bandettini PA. Twenty years of functional MRI: the science and the stories. Neuroimage 2012;62:575-88 CrossRef Medline

5. Zhang D, Raichle ME. Disease and the brain's dark energy. Nat Rev Neurol 2010;6:15-28 CrossRef Medline

6. van den Heuvel MP, Hulshoff Pol HE. Exploring the brain network: a review on resting-state fMRI functional connectivity. Eur Neuropsychopharmacol 2010;20:519-34 CrossRef Medline

7. Barkhof F, Haller S, Rombouts SA. Resting-state functional MR imaging: a new window to the brain. Radiology 2014;272:29-49 CrossRef Medline

8. Lee MH, Smyser CD, Shimony JS. Resting-state fMRI: a review of methods and clinical applications. AJNR Am J Neuroradiol 2013;34: 1866-72 CrossRef Medline

9. Lv H, Wang Z, Tong E, et al. Resting-state functional MRI: everything that nonexperts have always wanted to know. AJNR Am J Neuroradiol 2018;39:1390-99 CrossRef Medline

10. Leuthardt EC, Guzman G, Bandt SK, et al. Integration of resting state functional MRI into clinical practice: a large single institution experience. PLoS One 2018;13:e0198349 CrossRef Medline

11. Hou BL, Bhatia S, Carpenter JS. Quantitative comparisons on hand motor functional areas determined by resting state and task BOLD fMRI and anatomical MRI for pre-surgical planning of patients with brain tumors. Neuroimage Clin 2016;11:378-87 CrossRef Medline

12. Parker Jones O, Voets NL, Adcock JE, et al. Resting connectivity predicts task activation in pre-surgical populations. Neuroimage Clin 2016;13:378-85 CrossRef Medline

13. Lu J, Zhang $\mathrm{H}$, Hameed NU, et al. An automated method for identifying an independent component analysis-based language-related resting-state network in brain tumor subjects for surgical planning. Sci Rep 2017;7:13769 CrossRef Medline

14. Branco P, Seixas D, Deprez S, et al. Resting-state functional magnetic resonance imaging for language preoperative planning. Front Hum Neurosci 2016;10:11 CrossRef Medline

15. Kollndorfer K, Fischmeister FP, Kasprian G, et al. A systematic investigation of the invariance of resting-state network patterns: is resting-state fMRI ready for pre-surgical planning? Front Hum Neurosci 2013;7:95 CrossRef Medline

16. Sundermann B, Herr D, Schwindt W, et al. Multivariate classification of blood oxygen level-dependent fMRI data with diagnostic intention: a clinical perspective. AJNR Am J Neuroradiol 2014;35: 848-55 CrossRef Medline

17. Wolfers T, Buitelaar JK, Beckmann CF, et al. From estimating activation locality to predicting disorder: a review of pattern recognition for neuroimaging-based psychiatric diagnostics. Neurosci Biobehav Rev 2015;57:328 -49 CrossRef Medline

18. Rathore S, Habes M, Iftikhar MA, et al. A review on neuroimagingbased classification studies and associated feature extraction methods for Alzheimer's disease and its prodromal stages. Neuroimage 2017;155:530-48 CrossRef Medline

19. de Vos F, Koini M, Schouten TM, et al. A comprehensive analysis of resting state fMRI measures to classify individual patients with Alzheimer's disease. Neuroimage 2018;167:62-72 CrossRef Medline

20. Elliott L, Sharp K, Alfaro-Almagro F, et al. Genome-wide association studies of brain structure and function in the UK biobank. bioRxiv 2018:178806 CrossRef

21. Kim SG, Ogawa S. Biophysical and physiological origins of blood oxygenation level-dependent fMRI signals. J Cereb Blood Flow Metab 2012;32:1188-206 CrossRef Medline

22. Langner S, Buelow R, Fleck S, et al. Management of intracranial incidental findings on brain MRI. Rofo 2016;188:1123-33 CrossRef Medline

23. Sandeman EM, Hernandez Mdel C, Morris Z, et al. Incidental findings on brain MR imaging in older community-dwelling subjects are common but serious medical consequences are rare: a cohort study. PLoS One 2013;8:e71467 CrossRef Medline

24. Bos D, Poels MM, Adams HH, et al. Prevalence, clinical management, and natural course of incidental findings on brain MR images: the population-based Rotterdam scan study. Radiology 2016;281:507-15 CrossRef Medline

25. Morris Z, Whiteley WN, Longstreth WT, Jr, et al. Incidental findings on brain magnetic resonance imaging: systematic review and metaanalysis. BMJ 2009;339:b3016 CrossRef Medline

26. Vernooij MW, Ikram MA, Tanghe HL, et al. Incidental findings on brain MRI in the general population. $N$ Engl J Med 2007;357: 1821-28 CrossRef Medline

27. Borra RJ, Sorensen AG. Incidental findings in brain MRI research: what do we owe our subjects? J Am Coll Radiol 2011;8:848-52 CrossRef Medline 
28. Lasjaunias $P$, Burrows $P$, Planet C. Developmental venous anomalies (DVA): the so-called venous angioma. Neurosurg Rev 1986;9:233-42 CrossRef Medline

29. Lee M, Kim MS. Image findings in brain developmental venous anomalies. J Cerebrovasc Endovasc Neurosurg 2012;14:37-43 CrossRef Medline

30. Sarwar M, McCormick WF. Intracerebral venous angioma: case report and review. Arch Neurol 1978;35:323-25 CrossRef Medline

31. Ruíz DS, Yilmaz H, Gailloud P. Cerebral developmental venous anomalies: current concepts. Ann Neurol 2009;66:271-83 CrossRef Medline

32. Jung HN, Kim ST, Cha J, et al. Diffusion and perfusion MRI findings of the signal-intensity abnormalities of brain associated with developmental venous anomaly. AJNR Am J Neuroradiol 2014;35:1539-42 CrossRef Medline

33. Teuber A, Sundermann B, Kugel H, et al. MR imaging of the brain in large cohort studies: feasibility report of the population- and patient-based BiDirect study. Eur Radiol 2017;27:231-38 CrossRef Medline

34. Teismann $H$, Wersching $H$, Nagel $M$, et al. Establishing the bidirectional relationship between depression and subclinical arteriosclerosis: rationale, design, and characteristics of the BiDirect study. BMC Psychiatry 2014;14:174 CrossRef Medline

35. Beckmann CF, DeLuca M, Devlin JT, et al. Investigations into resting-state connectivity using independent component analysis. Philos Trans R Soc Lond B Biol Sci 2005;360:1001-13 CrossRef Medline

36. Griffanti L, Douaud G, Bijsterbosch J, et al. Hand classification of fMRI ICA noise components. Neuroimage 2017;154:188-205 CrossRef Medline

37. Salimi-Khorshidi G, Douaud G, Beckmann CF, et al. Automatic denoising of functional MRI data: combining independent component analysis and hierarchical fusion of classifiers. Neuroimage 2014;90:449-68 CrossRef Medline

38. Griffanti L, Salimi-Khorshidi G, Beckmann CF, et al. ICA-based artefact removal and accelerated fMRI acquisition for improved resting state network imaging. Neuroimage 2014;95:232-47 CrossRef Medline

39. Smith SM, Jenkinson M, Woolrich MW, et al. Advances in functional and structural MR image analysis and implementation as FSL. Neuroimage 2004;23(Suppl 1):S208-19 CrossRef Medline

40. Jenkinson M, Beckmann CF, Behrens TE, et al. FSL. Neuroimage 2012;62:782-90 CrossRef Medline

41. Jenkinson M, Bannister P, Brady M, et al. Improved optimization for the robust and accurate linear registration and motion correction of brain images. Neuroimage 2002;17:825-41 CrossRef Medline

42. Smith SM. Fast robust automated brain extraction. Hum Brain Mapp 2002;17:143-55 CrossRef Medline

43. Beckmann CF, Smith SM. Probabilistic independent component analysis for functional magnetic resonance imaging. IEEE Trans Med Imaging 2004;23:137-52 CrossRef Medline

44. Minka T. Automatic choice of dimensionality for PCA: technical report 514. MIT Media Lab Vision and Modeling Group. 2000. https://tminka.github.io/papers/pca/minka-pca.pdf. Accessed April 12,2017

45. Hyvärinen A. Fast and robust fixed-point algorithms for independent component analysis. IEEE Trans Neural Netw 1999;10:626-34 CrossRef Medline

46. Greve DN, Fischl B. Accurate and robust brain image alignment using boundary-based registration. Neuroimage 2009;48:63-72 CrossRef Medline

47. Lehéricy S, Biondi A, Sourour N, et al. Arteriovenous brain malformations: is functional MR imaging reliable for studying language reorganization in patients? Initial observations. Radiology 2002;223:672-82 CrossRef Medline

48. Kroll H, Soares BP, Saloner D, et al. Perfusion-CT of developmental venous anomalies: typical and atypical hemodynamic patterns. J Neuroradiol 2010;37:239-42 CrossRef Medline

49. Camacho DL, Smith JK, Grimme JD, et al. Atypical MR imaging perfusion in developmental venous anomalies. AJNR Am J Neuroradiol 2004;25:1549-52 Medline

50. Hanson EH, Roach CJ, Ringdahl EN, et al. Developmental venous anomalies: appearance on whole-brain CT digital subtraction angiography and CT perfusion. Neuroradiology 2011;53:331-41 CrossRef Medline

51. Sharma A, Zipfel GJ, Hildebolt C, et al. Hemodynamic effects of developmental venous anomalies with and without cavernous malformations. AJNR Am J Neuroradiol 2013;34:1746-51 CrossRef Medline

52. Iv M, Fischbein NJ, Zaharchuk G. Association of developmental venous anomalies with perfusion abnormalities on arterial spin labeling and bolus perfusion-weighted imaging. J Neuroimaging 2015;25: 243-50 CrossRef Medline

53. Larvie M, Timerman D, Thum JA. Brain metabolic abnormalities associated with developmental venous anomalies. AJNR Am J Neuroradiol 2015;36:475-80 CrossRef Medline

54. Kelly RE Jr, Alexopoulos GS, Wang Z, et al. Visual inspection of independent components: defining a procedure for artifact removal from fMRI data. J Neurosci Methods 2010;189:233-45 CrossRef Medline

55. Murphy K, Birn RM, Bandettini PA. Resting-state fMRI confounds and cleanup. Neuroimage 2013;80:349-59 CrossRef Medline

56. Thomas CG, Harshman RA, Menon RS. Noise reduction in BOLD-based fMRI using component analysis. Neuroimage 2002; 17:1521-37 CrossRef Medline

57. Beall EB, Lowe MJ. Isolating physiologic noise sources with independently determined spatial measures. Neuroimage 2007;37:1286300 CrossRef Medline

58. Perlbarg V, Bellec P, Anton JL, et al. CORSICA: correction of structured noise in fMRI by automatic identification of ICA components. Magn Reson Imaging 2007;25:35-46 CrossRef Medline

59. Sui J, Adali T, Pearlson GD, et al. An ICA-based method for the identification of optimal FMRI features and components using combined group-discriminative techniques. Neuroimage 2009;46: 73-86 CrossRef Medline

60. Storti SF, Formaggio E, Nordio R, et al. Automatic selection of resting-state networks with functional magnetic resonance imaging. Front Neurosci 2013;7:72 CrossRef Medline

61. Bhaganagarapu K, Jackson GD, Abbott DF. An automated method for identifying artifact in independent component analysis of resting-state FMRI. Front Hum Neurosci 2013;7:343 CrossRef Medline

62. Tohka J, Foerde K, Aron AR, et al. Automatic independent component labeling for artifact removal in fMRI. Neuroimage 2008;39: 1227-45 CrossRef Medline

63. De Martino F, Gentile F, Esposito F, et al. Classification of fMR independent components using IC-fingerprints and support vector machine classifiers. Neuroimage 2007;34:177-94 CrossRef Medline

64. Sochat V, Supekar K, Bustillo J, et al. A robust classifier to distinguish noise from fMRI independent components. PLoS One 2014;9: e95493 CrossRef Medline

65. Caballero-Gaudes C, Reynolds RC. Methods for cleaning the BOLD fMRI signal. Neuroimage 2017;154:128-49 CrossRef Medline

66. Pereira VM, Geibprasert S, Krings T, et al. Pathomechanisms of symptomatic developmental venous anomalies. Stroke 2008;39: 3201-15 CrossRef Medline

67. Tomycz ND, Vora NA, Kanal E, et al. Intracranial arterialized venous angioma: case report with new insights from functional brain MRI. Diagn Interv Radiol 2010;16:13-15 CrossRef Medline

68. Lowe MJ, Mock BJ, Sorenson JA. Functional connectivity in single and multislice echoplanar imaging using resting-state fluctuations. Neuroimage 1998;7:119-32 CrossRef Medline 